\title{
Parathyroid Adenoma Radiation Dose Simulator
}

\author{
*John Gough, CHP, MS, Radiation Safety Office, Department of Radiology, Marshfield Clinic, Marshfield, Wisconsin \\ Mark Anliker, CNMT, Waukesha Memorial Hospital, Milwaukee, Wisconsin \\ Michael E. Spieth, MD, Nuclear Medicine Section, Department of Radiology, Marshfield Clinic, Marshfield, Wisconsin \\ Darcy L. Kasner, Marshfield Clinic Research Foundation, Marshfield, Wisconsin \\ *Current affiliation: Swedish Medical Center, Seattle, Washington
}

\begin{abstract}
INTRODUCTION

As the number of radioisotope localization cases increased at our facility, the pathologists expressed concern regarding radiation exposure from parathyroid specimens. The radiation safety officer was consulted to analyze personnel radiation protection issues.

METHODS

Analysis of simulated specimens was performed for a range of activities and masses corresponding to the values that have been observed. The radiation dose rates from these samples were measured using a Ludlum Model $14 \mathrm{C}$ survey meter with a Model 44-38 energy compensated GM probe and a Ludlum Model 3 Geiger counter with a Model 44-9 "pancake" style GM probe (Ludlum Measurements, Inc., Sweetwater, Texas). Additionally, 3 consecutive 10-second counts were performed using a USSC Navigator Gamma Guidance System (United States Surgical Corporation, Norwalk, CT). The per-second average readings were recorded.
\end{abstract}

RESULTS

Our sample count-rates ranged from 139 to 2,830 counts/second. The majority of these values fell within the 100 to 1,000 count/second range typically observed during surgery. Based on our sample set, our dose rates at contact with these samples ranged from 0.17 to $4.0 \mathrm{mR} /$ hour depending on the instrument, sample activity, and sample volume. The variation between count rate and dose rate for each observed volume varied linearly with activity.

CONCLUSION

Based on these observed radiation doses, we concluded that there is no need to hold parathyroid specimens for 24 to 48 hours after surgical removal for handling because the typical radiation doses are quite low and would not result in significant radiation exposure to pathology personnel.

REPRINT REQUESTS:

Michael E. Spieth, MD

Nuclear Medicine Section

Department of Radiology

Mailstop: $\mathrm{H}-1 \mathrm{~N}-\mathrm{HM}$

Marshfield Clinic

1000 North Oak Avenue

Marshfield, WI 54449

Telephone: 800-782-8581

Fax: 715-387-7775

Email: spieth.michael@marshfieldclinic.org
KEYWORDS:

Parathyroid adenoma; Sestamibi; Hyperparathyroidism; Radiation dose; Radiation exposure 


\section{INTRODUCTION}

Parathyroid glands are located posterior to the thyroid gland at the superior and inferior poles of each lobe. The combined weight of all four glands is approximately $120 \mathrm{mg}$. Hyperparathyroidism occurs when one or more of the glands increases in size and produces additional parathyroid hormone. An elevated parathyroid hormone increases serum calcium, bone resorption, and urinary calcium loss for an overall effect of bone density loss. Decreased bone density creates a greater risk for fractures or breaks. In addition, increased blood calcium allows the muscles to exist in a state of tetany, unrelaxed, becoming more rigid with time.

Parathyroid localization studies are performed using technetium-99m (Tc-99m) labeled Cardiolite (sestamibi, Bristol-Myers Squibb Medical Imaging, Bellerica, NJ) that localizes in thyroid and abnormal parathyroid tissue. Typically, the relative abundance of radioactivity is highest in abnormal parathyroid tissue. Therefore, nuclear medicine imaging techniques can assist surgeons in determining the relative location of abnormal parathyroid tissue. During surgery the surgeon makes a small incision in the neck and uses a specially designed gamma radiation detector to determine the exact location of the abnormal parathyroid tissue.

With the increased number of radioisotope localization cases, pathologists at our facility expressed concern regarding radiation exposure. The guidelines by Miner et $\mathrm{al}^{1}$ on the safe use of radioactive materials during localization and resection of sentinel lymph nodes was consulted. The guidelines indicate that radioactive parathyroid specimens are to be held for decay until they near background radiation levels.
With a physical half-life of 6 hours for Tc-99m, the recommended holding period prior to processing ranged from 24 to 48 hours. The pathologists were concerned about the impact that the delay of specimen processing would have on the timeliness of histological diagnosis and ultimately patient care. The radiation safety officer was consulted to determine the appropriate balance that would address staff radiation protection and timely specimen processing and diagnosis.

The average radioactivity between lymphatic specimens compared to parathyroid specimens differs by as much as a factor of 20, with lymphatic specimens containing the greater concentration. The counting analysis and instrument readings obtained from the surgical parathyroid specimens ranged from a radioactivity level between 1 and $10 \mu \mathrm{Ci}$.

To the best of our knowledge, the published research on staff radiation exposure has focused on the handling of sentinel lymph nodes; studies have not been conducted that evaluate radiation exposure from parathyroid adenomas.

\section{OBJECTIVE}

The objective of this study was to determine the radiation dose that would result from the handling of parathyroid samples, following parathyroid localizing studies. Additionally, a method for calculating an estimated dose from a parathyroid sample prior to handling these specimens was researched.

\section{METHODS}

Since attenuation of radiation by body tissue can be approximated by water, samples were prepared that represented typical parathyroid specimens. ${ }^{2}$ A plastic-walled container was used to minimize attenuation and approximate body tissue. ${ }^{3}$ A $3 \mathrm{~mL}$ plastic liquid scintillation tube held the simulated specimens.

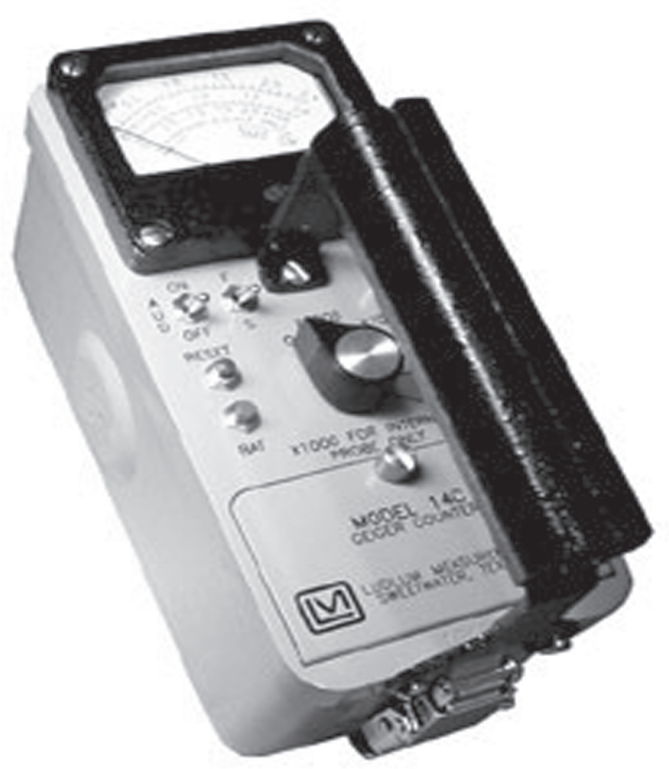

Figure 1. Model 14C Geiger Counter.

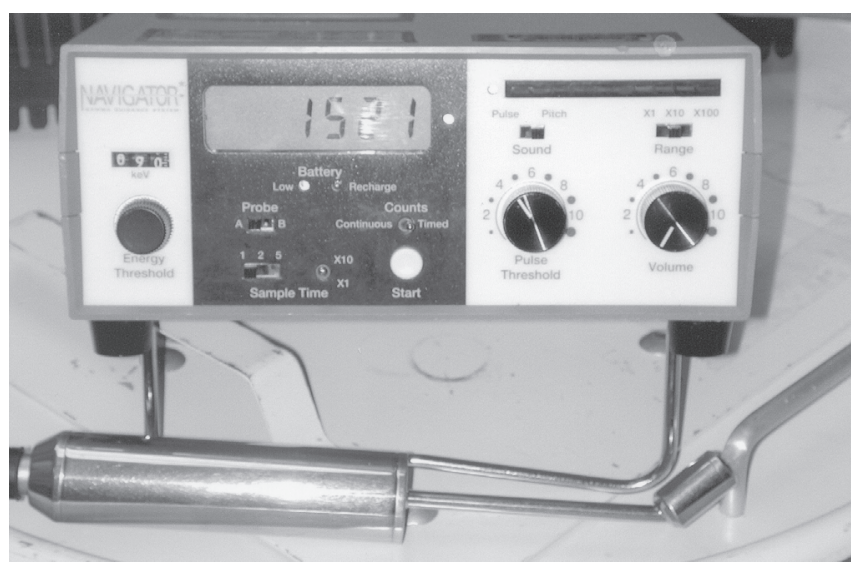

Figure 2. USSC Navigator Gamma Guidance System. 
Based on prior experience with parathyroid tissues from pathology reports, it was determined that a range of 50 to $1,500 \mu \mathrm{L}$ (or 0.05 to $1.5 \mathrm{~mL}$ ) of water would approximate the parathyroid masses that typically ranged from 100 to $1,650 \mathrm{mg}$. A Capintec CRC-15 dose calibrator (Capintec, Ramsey, NJ) was used for the initial activity determination. The measurement of the initial activity was approximately 1 $\mathrm{mCi}$ of Tc-99m in a known volume, which was determined by pipetting a $50 \mu \mathrm{L}$ sample from the radioactive stock solution. This known activity was then diluted to a concentration of approximately $1 \mu \mathrm{Ci} / \mu \mathrm{L}$ using a $0.9 \%$ saline solution. Seven base samples with activities ranging from 1.1 to $12.2 \mu \mathrm{Ci}$ of Tc-99m were placed in the $3-\mathrm{mL}$ liquid scintillation tubes. The samples were brought to an initial volume of $50 \mu \mathrm{L}$ and then increased to volumes of 100 , $250,500,750,1,000$, and $1,500 \mu \mathrm{L}$.

The radiation dose rates from these samples were measured using a Ludlum Model 14C Geiger counter (Ludlum Measurements, Inc., Sweetwater, Texas), with a Model 4438 energy compensated GM probe, and a Ludlum Model 3 Geiger counter with a Model 44-9 "pancake" style GM probe (figure 1). GM counters were selected based on their availability, cost, ease of operation, and the ability to perform simple data reproduction. However, since the detector for the Ludlum Model 3 is not energy compensated, dose rate references from this meter are not accurate.

Additionally, three consecutive 10-second counts were performed and the average reading calculated to correlate dose rates to the actual counting instrument used during surgery. The counts were conducted with a USSC Navigator Gamma Guidance System (United States Surgical Corporation, Norwalk, CT [figure 2]).

\section{RESULTS}

The sample count rate range was 139 to 2,830 counts/second. These values fell within the range observed during surgery, 100 to 1,000 counts/second. Based on the sample set, the dose rate range at contact was 0.17 to $4.0 \mathrm{mR} /$ hour, dependent on the instrument, sample activity, and sample volume. Dose rates at $30 \mathrm{~cm}$ (12") from the samples to approximate staff body doses were also measured. Variations from background radiation levels for any of the samples at this distance were not noted. The graphs presented in figures 3, 4 and 5, are sample volumes that represent the most commonly observed parathyroid masses.

As expected, the variation between count rate and dose for each observed volume varied linearly with activity. This outcome allowed for the creation of cross-referenced graphs to predict the expected contact dose rates for a known parathyroid mass based on observed count rates in the operating room.

\section{CONCLUSION}

Processing of an individual parathyroid sample is completed in less then 20 minutes. The primary concern was the dose that would be encountered by the hand or extremity from handling the radioactive sample.

The Nuclear Regulatory Commission is responsible for regulations governing the use of byproduct radioactive materials. Thus Tc- $99 \mathrm{~m}$ is reactor generated radioactive material, radiation exposure to this product falls under the purview of the Nuclear Regulatory Commission.

Title 10 of the Code of Federal Regulations, Chapter 1, Part 20.1201(2)(ii), limits the radiation dose to the extremities to 50 rem/year. Additionally, Part 20.1502(1) specifies that external monitoring of radiation dose is required for adults who are expected to receive doses in excess of $10 \%$ of the annual dose limits.

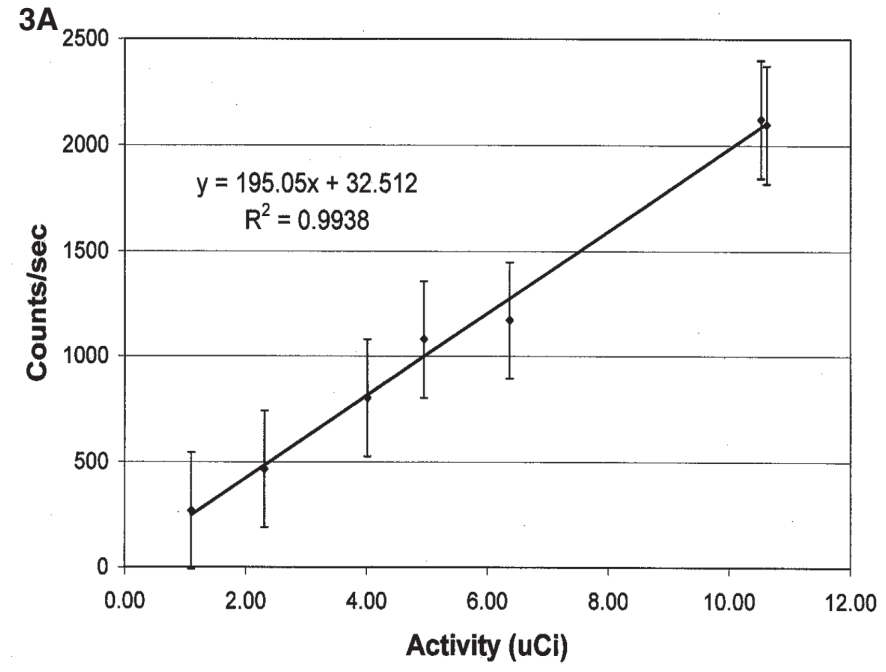

Figure 3A. Activity vs. counts, Navigator, $250 \mu \mathrm{L}$ sample.

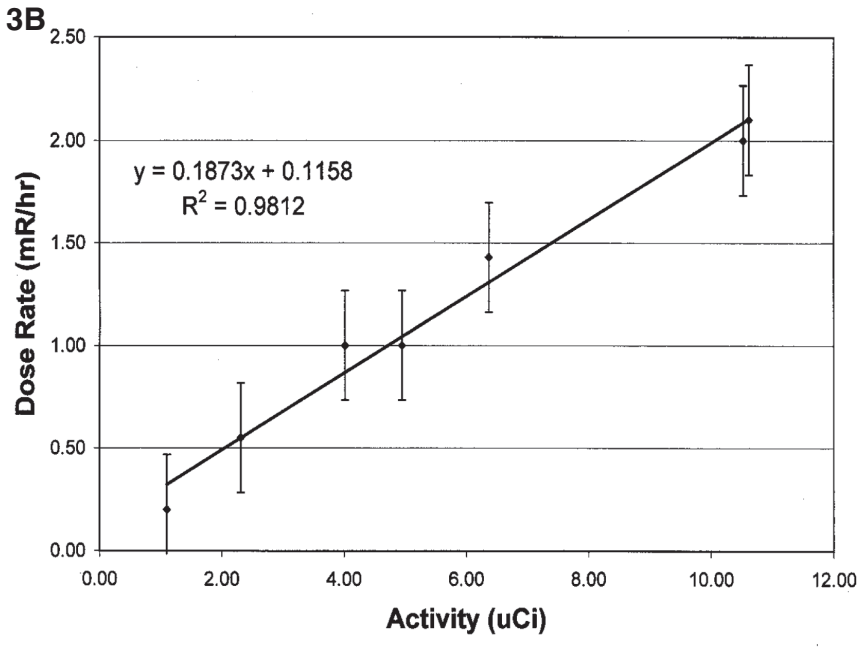

Figure 3B. Activity vs. dose rate, Ludlum 14C , $250 \mu \mathrm{L}$ sample. 
4A

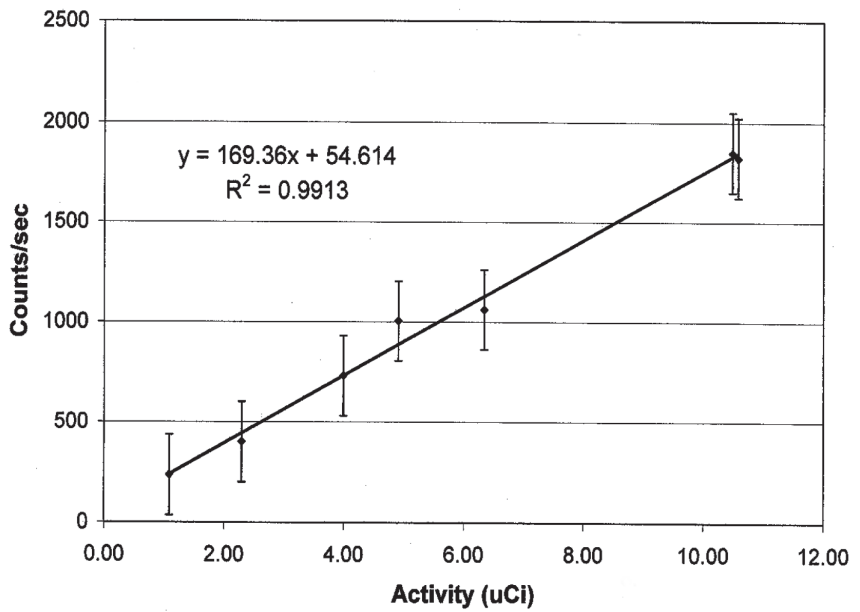

Figure 4A. Activity vs. counts per second, Navigator, $500 \mu \mathrm{L}$ sample.

$5 A$

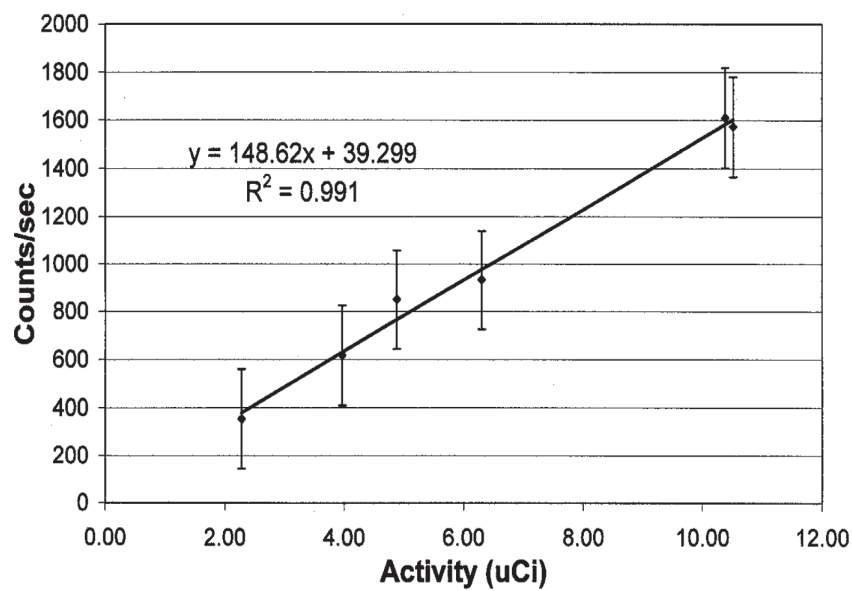

Figure 5A. Activity vs. counts, Navigator, $750 \mu \mathrm{L}$ sample.

Based on our experimental observations, it is highly improbable for an individual who handles parathyroid samples to receive a dose in excess of $10 \%$ of the annual dose limits (permissible dose limits are $5 \mathrm{rem} / \mathrm{year}$ to the extremities). Even if an individual was exposed to the maximum observed dose rate of $4 \mathrm{mR} /$ hour and handled each sample for the typical processing time of 20 minutes, it would take approximately 3,750 samples to reach a hand dose of 5 rem.

Pathologists at this particular facility process, on average, 50 specimens per year. If only one pathologist processed every specimen, the maximum hand dose to that individual would be $<130 \mathrm{mrem}$. Therefore, the conclusion was that there is no need to hold specimens for 24 to 48 hours after surgical removal for handling because predicted radiation doses are quite low. The data provides an estimation of the radiation doses that can be expected from handling these samples, and assurance that radiation exposure is minimal.
4B

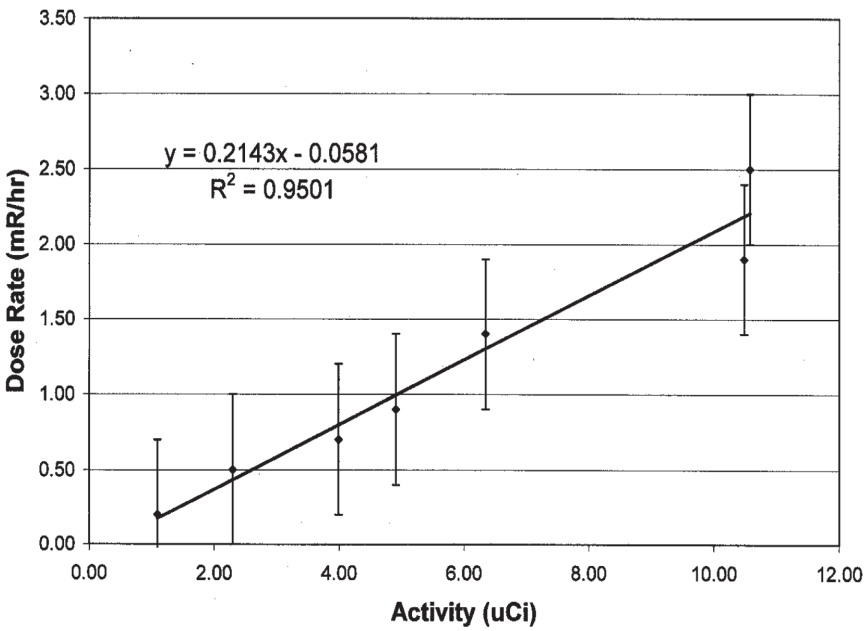

Figure 4B. Activity vs. dose rate, Ludlum 14C, $500 \mu \mathrm{L}$ sample.

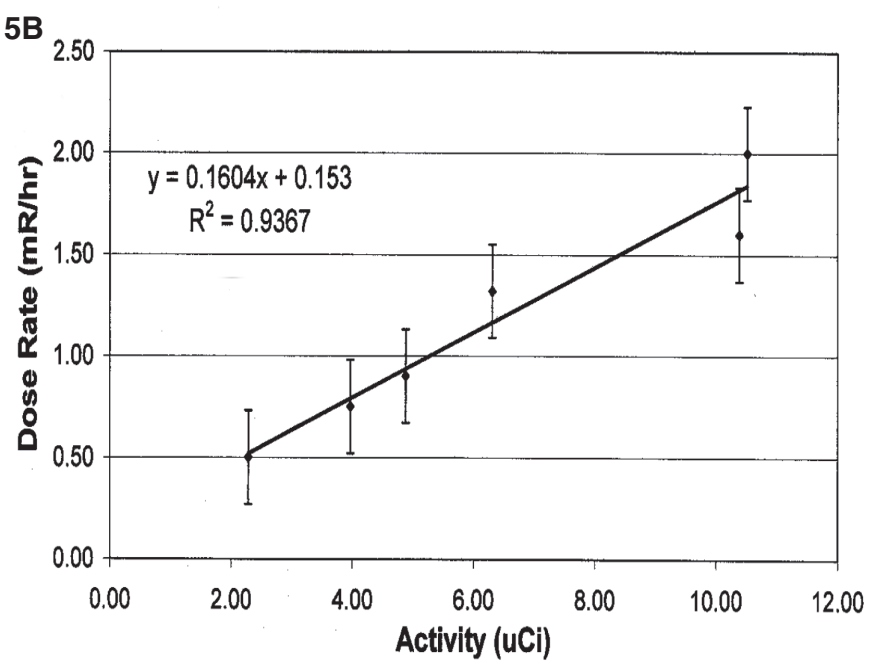

Figure 5B. Activity vs. dose rate, Ludlum 14C, $750 \mu \mathrm{L}$ sample.

\section{ACKNOWLEDGMENTS}

We would like to thank Diana M. Spieth, BS for her help with the figures and Marshfield Clinic Research Foundation for its support in the preparation of this manuscript through the efforts of Alice Stargardt.

\section{REFERENCES}

1. Miner TJ, Shriver CD, Flicek PR, Miner FC, Jaques DP, Maniscalco-Theberge ME, Krag DN. Guidelines for the safe use of radioactive materials during localization and resection of the sentinel lymph node. Ann Surg Oncol 1999;6:75-82.

2. Etherington H. Nuclear engineering handbook. New York: McGraw-Hill; 1958.

3. Shleien B. The health physics and radiological health handbook. Revised ed. Silver Spring MD: Scinta Inc; 1992. 